\title{
QUEEN'S
UNIVERSITY
BELFAST
}

\section{A repairable carbon nanotube web-based electro-thermal heater and damage sensor for aerospace applications}

Yao, X., Falzon, B., \& Hawkins, S. (2021). A repairable carbon nanotube web-based electro-thermal heater and damage sensor for aerospace applications. The Aeronautical Journal, 1-11. https://doi.org/10.1017/aer.2021.40

Published in:

The Aeronautical Journal

Document Version:

Peer reviewed version

Queen's University Belfast - Research Portal:

Link to publication record in Queen's University Belfast Research Portal

Publisher rights

Copyright 2021 CUP.

This manuscript is distributed under a Creative Commons Attribution-NonCommercial-NoDerivs License

(https://creativecommons.org/licenses/by-nc-nd/4.0/), which permits distribution and reproduction for non-commercial purposes, provided the author and source are cited.

\section{General rights}

Copyright for the publications made accessible via the Queen's University Belfast Research Portal is retained by the author(s) and / or other copyright owners and it is a condition of accessing these publications that users recognise and abide by the legal requirements associated with these rights.

Take down policy

The Research Portal is Queen's institutional repository that provides access to Queen's research output. Every effort has been made to ensure that content in the Research Portal does not infringe any person's rights, or applicable UK laws. If you discover content in the Research Portal that you believe breaches copyright or violates any law, please contact openaccess@qub.ac.uk. 


\section{The Aeronautical Journal}

\section{A Repairable Carbon Nanotube Web Based Electro-Thermal Heater and Damage Sensor for Aerospace Applications \\ --Manuscript Draft--}

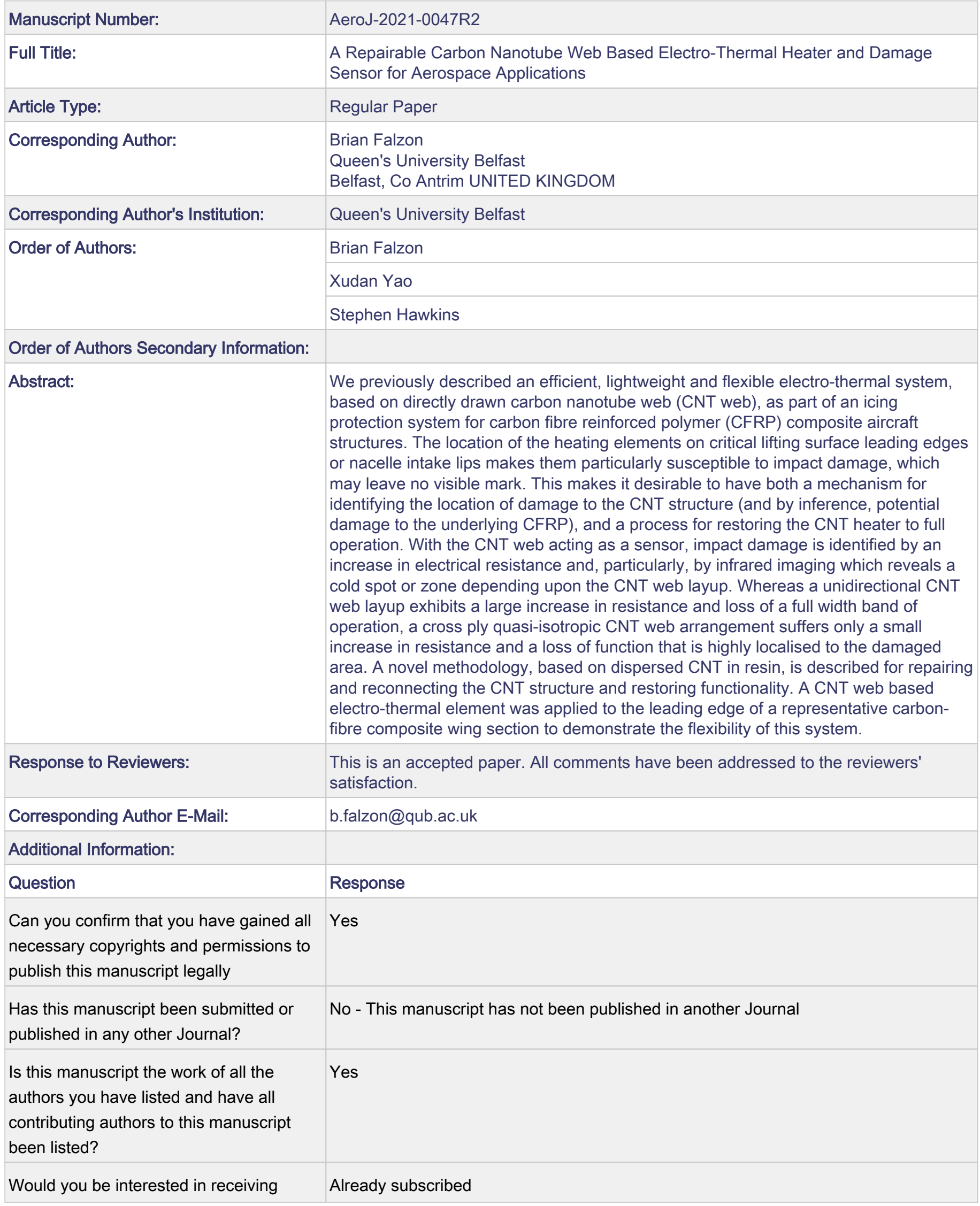


information about subscribing to The

Aeronautical Journal?

Would you be interested in receiving

Already a member

information about the benefits of

becoming a member of The Royal

Aeronautical Society?

Are you below the age of 30 and wish to

No

be considered for the Young Person's

Written Prize Award?

Would you be interested in having your

No

paper printed in colour in the hardcopy

version of the Aeronautical Journal?

Are you submitting any figures that should No

be reproduced in colour in the printed

article? (Please note that you may be

required to pay a fee for colour printing.

Refer to the journal's instructions for

authors.)

Are you submitting any supplementary

No

material (eg additional figures, tables) for

online publication only?

Select the Special Issue to which you are submitting your manuscript. If you are not submitting to a Special Issue, please

select "Not part of a Special Issue."

Is it your intention to have your paper

No

published under the 'Gold' option Open

Access initiative, for which there is a

charge?

Author Comments: 


\title{
A Repairable Carbon Nanotube Web Based Electro-Thermal Heater and Damage Sensor for Aerospace Applications
}

\author{
Xudan Yao ${ }^{1,2}$, Stephen C. Hawkins ${ }^{2,3}$, and Brian G. Falzon ${ }^{2, *}$ \\ ${ }^{1}$ Department of Materials, Henry Royce Institute and National Graphene Institute, University \\ of Manchester, Oxford Road, Manchester, M13 9PL, UK \\ ${ }^{2}$ Advanced Composites Research Group, School of Mechanical and Aerospace Engineering, \\ Queen's University Belfast, Belfast, BT9 5AH, UK \\ ${ }^{3}$ Department of Materials Science and Engineering, Monash University, Clayton, 3800, \\ Australia
}

\author{
*Corresponding Author: Fax: +44 (0)28 90974148

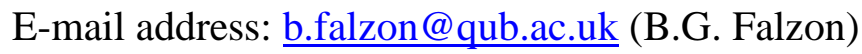

\begin{abstract}
We previously described an efficient, lightweight and flexible electro-thermal system, based on directly drawn carbon nanotube web (CNT web), as part of an icing protection system for carbon fibre reinforced polymer (CFRP) composite aircraft structures. The location of the heating elements on critical lifting surface leading edges or nacelle intake lips makes them particularly susceptible to impact damage, which may leave no visible mark. This makes it desirable to have both a mechanism for identifying the location of damage to the CNT structure (and by inference, potential damage to the underlying CFRP), and a process for restoring the CNT heater to full operation. With the CNT web acting as a sensor, impact damage is identified by an increase in electrical resistance and, particularly, by infrared imaging which reveals a cold spot or zone depending upon the CNT web layup. Whereas a unidirectional CNT web layup exhibits a large increase in resistance and loss of a full width band of operation, a cross
\end{abstract}


ply quasi-isotropic CNT web arrangement suffers only a small increase in resistance and a loss of function that is highly localised to the damaged area. A novel methodology, based on dispersed CNT in resin, is described for repairing and reconnecting the CNT structure and restoring functionality. A CNT web based electro-thermal element was applied to the leading edge of a representative carbon-fibre composite wing section to demonstrate the flexibility of this system.

Keywords: Carbon Nanotube Web, Electro-Thermal System, Repairable, Sensor, Flexible

\section{Nomenclature}

$\begin{array}{ll}\text { AI/DI } & \text { anti-icing/de-icing } \\ \text { CF } & \text { carbon fibre } \\ \text { CFRP } & \text { carbon fibre reinforced polymer } \\ \text { CNT } & \text { carbon nanotube } \\ \text { CVD } & \text { chemical vapour deposition } \\ \text { GF } & \text { glass fibre } \\ \text { GFRP } & \text { glass fibre reinforced polymer } \\ \text { ILFT } & \text { interlaminar fracture toughness } \\ \text { IR } & \text { Infrared } \\ \text { LSP } & \text { lightning strike protection } \\ \text { R } & \text { resistance } \\ \text { SEM } & \text { Scanning Electron Microscope } \\ \text { SHM } & \text { structural health monitoring } \\ \text { UD } & \text { unidirectional } \\ \Delta R & \text { resistance difference }\end{array}$




\section{Introduction}

Owing to its superior specific strength and stiffness, carbon fibre reinforced polymer (CFRP) composites are increasingly being used in diverse sectors such as marine, automotive, sports, and in particular, aerospace, where they comprise around half the weight of the primary structure of the latest generation wide-body passenger aircraft such as the Boeing 787 and A350 $\mathrm{XWB}^{(1)}$. This revolution in materials and fabrication, together with ever increasing pressure to reduce fuel consumption has provided the impetus for the development of multifunctional structures incorporating such functionality as structural health monitoring $(\mathrm{SHM})^{(2-5)}$, lightning strike protection (LSP) ${ }^{(6-10)}$ and improved ice protection systems ${ }^{(11-18)}$ whilst also delivering enhanced structural performance such as higher interlaminar fracture toughness (ILFT) ${ }^{(19-23)}$. 'Directly drawable carbon nanotube web' (CNT web) is a uniquely adaptable and useful material comprised of highly aligned, small multiwall CNT. It is electrically conductive particularly in the draw direction, extremely light and flexible, and highly compatible with composite materials. We have reported previously on the use of CNT web to address $\mathrm{SHM}^{(4)}$ and $\operatorname{ILFT}^{(19,20)}$. We also described the creation of a CNT web-based electrothermal element as part of an AI/DI system for aerospace applications ${ }^{(11-13)}$. Such an AI/DI element would be located on the critical aircraft wing and nacelle lip leading edges, which are also the areas most susceptible to impact. Hence, the AI/DI elements would be the first to suffer impact damage (which may leave no visible mark), necessitating a mechanism to detect damaged areas and to repair them, and this is now reported. The laminate structure of CFRP composite also makes it susceptible to impact damage ${ }^{(24-27)}$. The mechanism for detection of damage to the AI/DI element also facilitates the localization of potential damage to the underlying CFRP composite, further enhancing the multifunctional value of CNT web. The flexibility of the CNT web-based 
electrothermal system was demonstrated by applying it to the leading edge surface of a representative composite wing section.

\section{Experimental section}

\subsection{Materials and sample preparation}

Woven Glass fibre (GF)/epoxy prepreg (RE295/SE84LV) and dry woven glass fabric (RE50P), with areal weights of 292 gsm and 47 gsm respectively, were supplied by Gurit (UK) Ltd. Unidirectional spread tow carbon fibre (UTS50S) thin ply, with an areal weight of $32 \mathrm{gsm}^{(28)}$, was supplied by TeXtreme (Sweden). IN2 epoxy resin and copper foil $(0.025 \mathrm{~mm}$ thick, annealed, uncoated, 99.8\%) were purchased from Easy Composites (UK) and Alfa Aesar (UK) respectively. Highly aligned 'forests' of long thin few-wall CNT were fabricated in-house by chemical vapour deposition (CVD) (Fig. 1a), grown on a silicon wafer with iron catalyst, yielding an average CNT length of $300 \mu \mathrm{m}$ (Fig. 1d,e), an average CNT diameter of $10 \mathrm{~nm}^{(29,30)}$ and an average wall number of around seven. CNT web was directly drawn from the CNT forests (Fig. 1b-e). The CNT web is highly aligned and anisotropic (orthotropic) ${ }^{(18)}$ with an electrical resistance in the draw direction $\left[0^{\circ}\right]$ only $\sim 4 \%$ of that in the transverse directions $\left[90^{\circ}\right]$ (Fig. 1).

Samples, with the number of CNT web layers and their alignment, were arranged in five different layups. Four samples comprised CNT web alone: $[0]_{10},[0]_{20} /[90]_{20},[45]_{20} /[-45]_{20}$ and $[0]_{5} /[45]_{5} /[-45]_{5} /[90]_{5}$, are denoted A to D. The fifth sample comprised a single layer of unidirectional (UD) thin ply carbon fibre in addition to twenty $0^{\circ} \mathrm{CNT}$ layers, $[0]_{20} /\left[90^{*}\right]$ and is denoted E. The thickness of 10 layers of CNT web in resin is $\sim 6 \mu \mathrm{m}$, resulting in an overall laminate thickness of $0.60 \mathrm{~mm}, 0.62 \mathrm{~mm}, 0.62 \mathrm{~mm}, 0.61 \mathrm{~mm}$ and $0.63 \mathrm{~mm}$ for sample A to E. The square heating element comprising the CNT (or CNT / UD thin ply) web stack was sandwiched between two layers of glass fibre reinforced polymer (GFRP) to electrically isolate 
it from a putative CFRP structure, and with copper foil buses at two opposite sides in the $90^{\circ}$ direction with a final sample size of $30 \mathrm{~mm} \times 30 \mathrm{~mm}$ (Fig. 1f). The assembly was prepared using the vacuum bagging technique and cured according to manufacturer (Gurit) specifications for SE84LV.

(a)

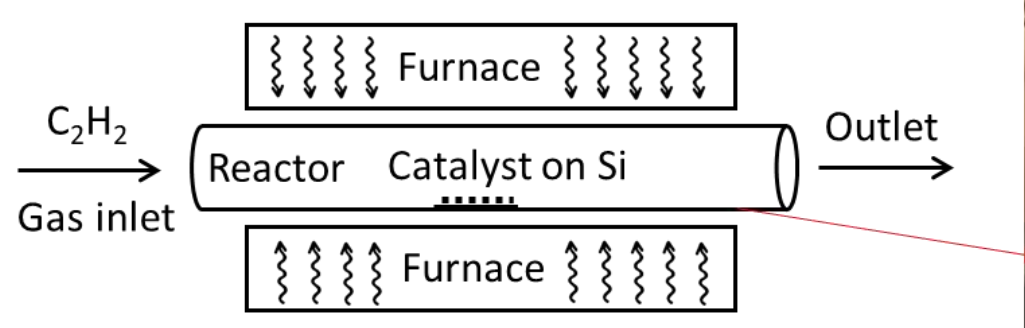

(b)

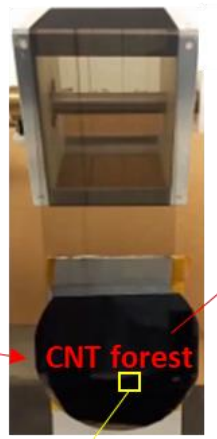

(c)
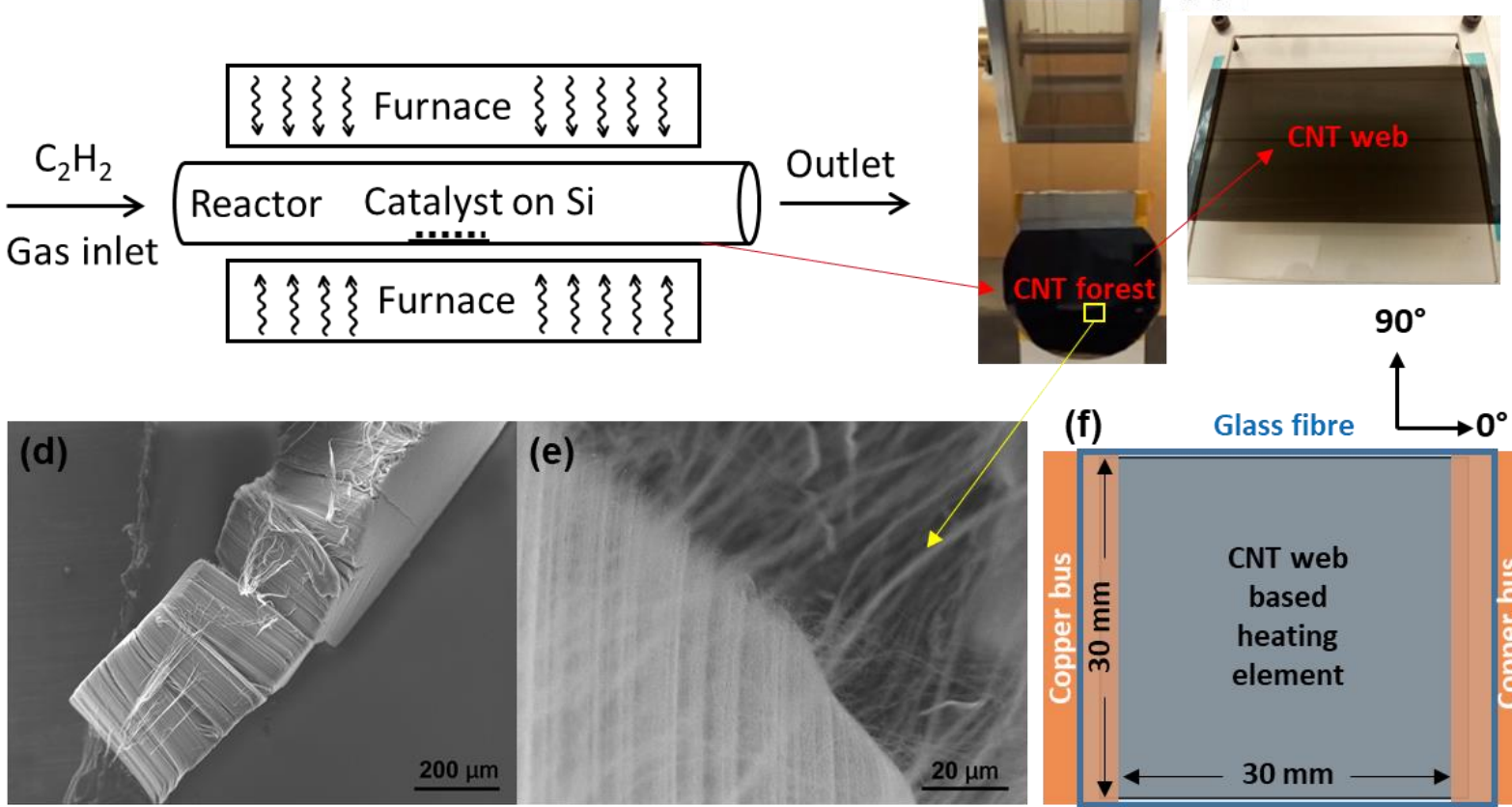

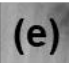

(e)

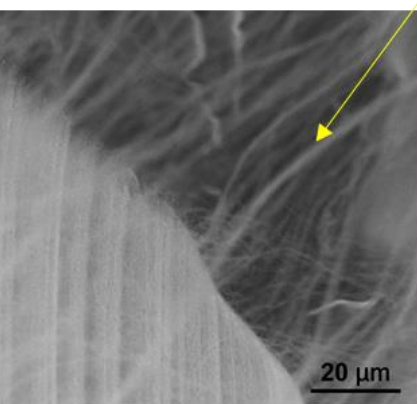

(f)

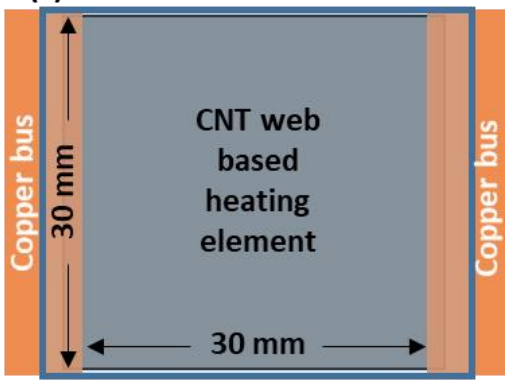

Figure 1. (a) Schematic of CVD. (b) Directly drawn CNT web from CNT forest. (c) CNT web on a mounting frame. SEM images of (d) CNT forest and (e) its drawing. (f) Sample specifications.

\subsection{Impact damage and repair methods}

In order to see the effect of impact damage on, and the repairability of the CNT web/GFRP electro-thermal system, an in-house constructed dropweight device based on the ASTM D7136 standard, with a $1.266 \mathrm{~kg}$ (Fig. 2a), $10 \mathrm{~mm}$ diameter hemispherical impactor, and impact energy of $3 \mathrm{~J}$ was used. The electrical resistance and thermal performance were measured before and after impact, and damaged samples inspected by SEM. The repair procedure (Fig. 2b-d), entailed preparation of a 1wt\% dispersion of the CNT forest in IN2 epoxy resin (resin and slow 
hardener mixed in the ratio of 100:30) through light roll milling for approximately 1 minute (Fig. 2c) using an in-house built miniature mill. The CNT forests grown by this CVD method are not only able to be drawn into webs, but also very easy to disperse uniformly in epoxy when processed properly. The highly viscous CNT/epoxy mixture was painted onto the impact damaged areas of each sample, which was then placed on an aluminium tool plate. A layer of peel ply and two layers of bleed fabric were applied to the top, and the cure procedure applied according to manufacturer (Easy Composites) specifications for IN2 through vacuum bagging (Fig. 2e).
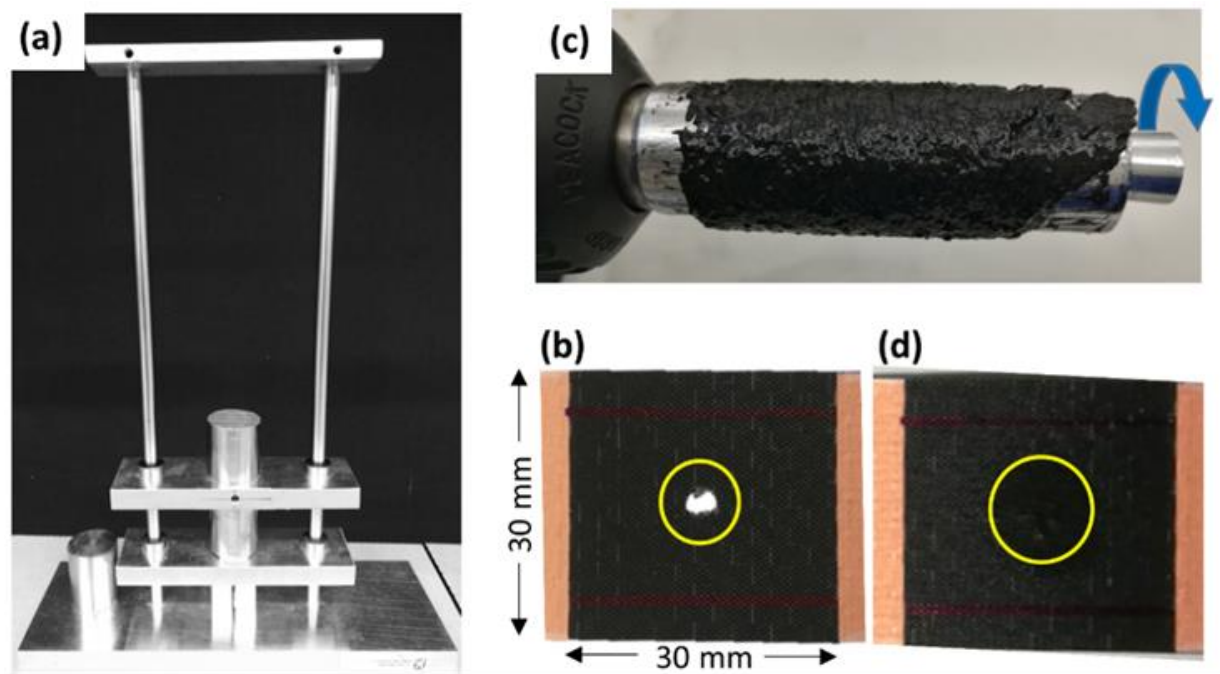

(e)

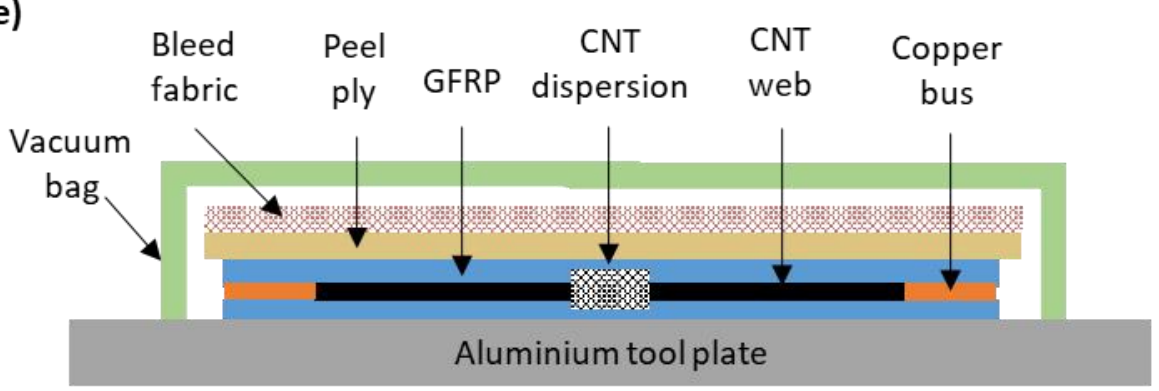

Figure 2. (a) In-house constructed impactors. (b) Sample D after impact. (c) CNTs dispersed in epoxy through roll milling. (d) Dispersed CNT applied to the damaged sample D for repair.

(e) Repair through vacuum bagging. 


\subsection{Characterization}

The resistive heating performance of the composites was investigated, with the voltage and current controlled by an EA Elektro-Automatik PS 3016-20B Digital Bench Power Supply operated at $10-12 \mathrm{~V}$ (maximum voltage / current: 16 V / $20 \mathrm{~A}$ ). The temperature distribution was monitored by a FLIR SC640 thermal imaging camera (640 x 480 pixels superior resolution, thermal sensitivity of $30 \mathrm{mK}, 2^{\circ} \mathrm{C}$ accuracy), with the samples held horizontally in a still air environment. An Agilent 34450A 51/2 Digit Multimeter was employed to measure the resistance of the samples using the 4-wire method. The morphology of CNTs was characterized by a Hitachi FlexSEM1000 Scanning Electron Microscope (SEM).

\section{Results and Discussion}

\subsection{Impact and repair performance of the CNT web based electro-thermal system}

Our previous work ${ }^{(11-13)}$ demonstrated the fabrication and performance of CNT web-based electrothermal elements for application in aerospace composites, and how the orthotropic character of the highly-aligned CNT web could be designed according to specific requirements ${ }^{(13)}$. As such systems would be placed on areas susceptible to impact damage, it was evident that a method to detect and repair such damage would be required and is here reported. The methodology depends on the phenomenon of 'sword in sheath' breakage commonly observed with small multiwall $\mathrm{CNT}^{(31)}$ where the outer wall in contact with the matrix fractures while the inner CNT structure partially pulls out before breaking. This creates a fringe of clean CNT (Fig. 3a,b) along the fracture line that can readily be reconnected. Use of a concentrated dispersion of the same CNT material ensures maximum conformability and connectivity across the break. Whereas the pristine heater uses highly aligned CNT web to capture the efficiency and flexibility of this material, the repair necessarily uses dispersed or 
disordered CNT, which is adequate for limited distance conduction that does not degrade the overall heater characteristics. Thus it should be noted that if a larger damaged region is removed in preparation of a scarf repair, the scale of the CNTs is such that nanoscale CNT protrusions would still be present around the edges. Under such circumstances it is anticipated that a plug patch prefabricated with aligned CNT web could be used with the edges being reconnected using the CNT dispersion.

\subsubsection{Unidirectional layup}

A simple unidirectional CNT web layup with few web layers (Sample A, [0] $]_{10}$ ), which is most susceptible to inhomogeneities in the web assembly ${ }^{(13)}$ was used to indicate the maximum effect of impact damage (Fig. 3c-e). As the CNT web has low transverse conductivity, heating in the undamaged specimen is slightly uneven (Fig 3c). However, the impact punched a nearly circular hole through the sample, and created an open circuit cold zone across the entire element (Fig. 3d) while the resistance increased by $17.8 \%$ (Table 1), which accords with the ratio of the 'dark' (cold) to 'bright' (heated) areas. In addition to being able to draw CNT forests into webs, the CVD CNTs are also very easy to disperse if processed appropriately. After the repair (Fig. $3 \mathrm{e}$ ), the resistance returned to the value before the impact (Table 1), suggesting that the dispersed CNTs are primarily reconnecting the broken CNT ends protruding from fractures (Fig. 3a,b) rather than forming a 'bypass' or 'auxiliary' heater in their own right.

Once repaired and cured, the broken heating path was almost fully recovered with only a relatively small drop in temperature at and around the impact site of the sample (Fig. 3e). This indicates that the heating characteristic of the mass of dispersed CNT is not quite as good as that of the CNT web. This may be improved by optimization of the CNT loading or resin cure. A better though slower approach to repairing a sizeable hole might be to prepare a CNT web / GFRP patch and join the edges with dispersed CNT in resin. Of particular note is that the 
heating element can also be used as a sensor by both electrical resistance measurement and especially by infrared (IR) imaging, as it shows the location of damage to the heater structure and, by inference, potential damage to the underlying composite.
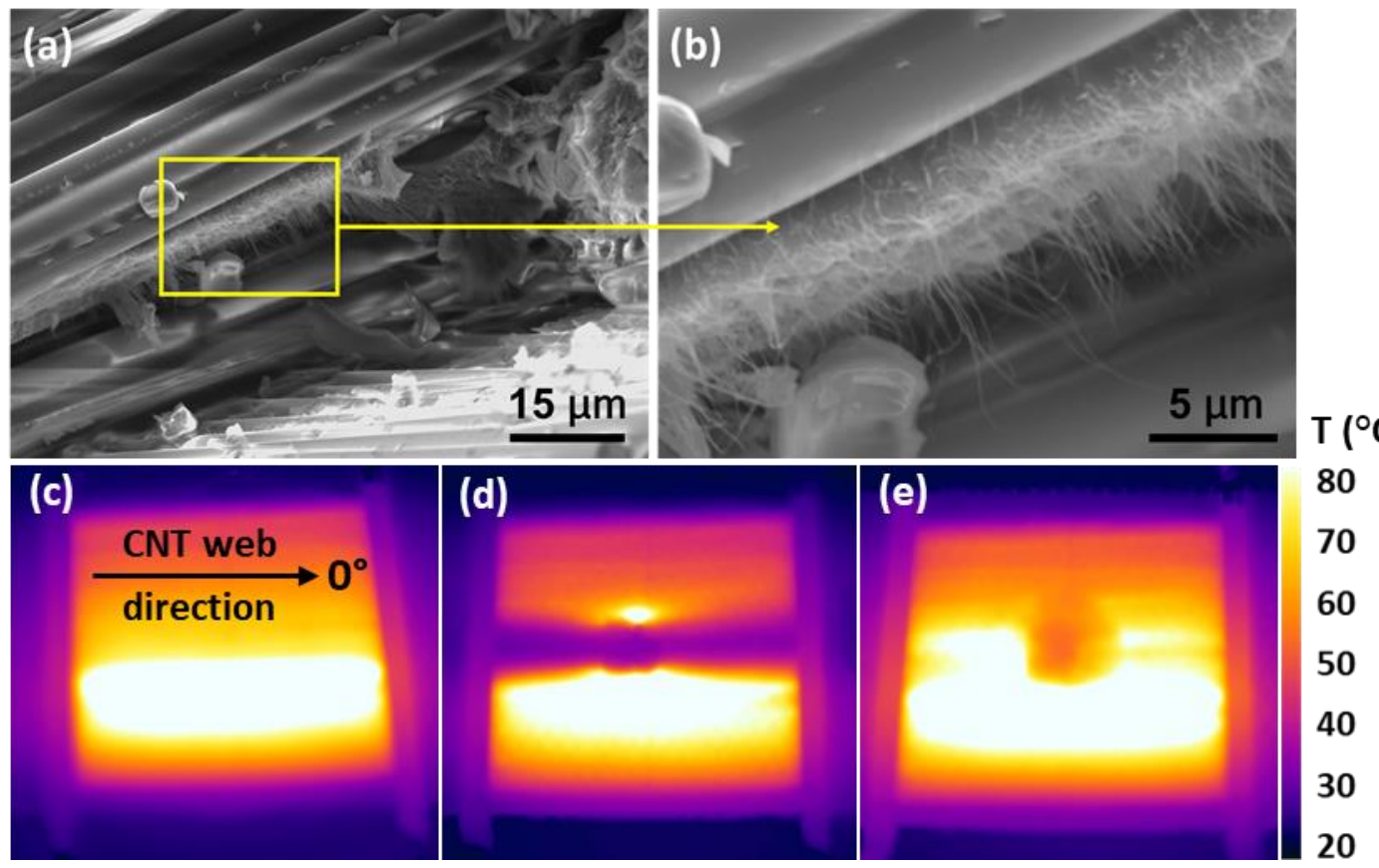

80

70

60

50

40

30

20

Figure 3. (a) SEM image of fracture edge of Sample A [0 $]_{10}$ after impact showing (b)

projecting CNT filaments. Thermal performance (c) before and (d) after impact and (e) after repair.

\subsubsection{Cross-ply layups}

As a heater with unidirectional CNT web loses a significant area of operation when damaged due to the open circuit and resulting linear unheated area (Fig. 3), it was of importance to determine if a different layup structure could make the heater more resilient to damage (i.e. continue functioning effectively), whilst also providing a better indication of the location and severity of damage. Elements comprising more layers of CNT web and with different layup pattern were prepared (Samples B,C,D). In addition, a CNT heater comprising 20 layers of unidirectional $\mathrm{CNT}$ web $\left(0^{\circ}\right)$ plus one orthogonal unidirectional 'thin ply' $\mathrm{CF}$ layer (i.e. at $90^{\circ}$ 
to the applied electric field) was prepared (Sample E, Table 1). The thin CF ply is approximately $15 \mu \mathrm{m}$ thick and contributes little to the conductivity or heating function as demonstrated by the resistance, which is very close to that for Sample B $\left(\left[0_{20} / 90_{20}\right]\right)$; however, it was anticipated from previous work ${ }^{(12)}$ to provide a useful bridging function for minimal additional weight.

\section{Table 1}

Resistance before and after the impact $(3 \mathrm{~J})$ for heaters with different layups

\begin{tabular}{|c|c|c|c|c|c|c|c|}
\hline Sample & $\begin{array}{c}\text { Heating } \\
\text { element - } \\
\text { CNT layup }\end{array}$ & $\begin{array}{c}\text { Voltage } \\
\text { applied } \\
\text { (V) }\end{array}$ & $\begin{array}{c}\text { R-before } \\
\text { impact } \\
(\Omega)\end{array}$ & $\begin{array}{c}\text { R-after } \\
\text { impact } \\
(\Omega)\end{array}$ & $\begin{array}{c}\Delta \mathbf{R}(\boldsymbol{\Omega}) \\
((\boldsymbol{\%}))\end{array}$ & $\begin{array}{c}\text { R-after } \\
\text { repair } \\
(\Omega)\end{array}$ & $\begin{array}{c}\text { Residual } \\
\Delta \mathbf{R} \\
(\Omega)((\%))\end{array}$ \\
\hline A & {$[0]_{10}$} & 12 & 56.2 & 66.2 & $10(18)$ & 56.2 & $0(0)$ \\
\hline B & {$\left[0_{20} / 90_{20}\right]$} & 10 & 25.6 & 26.0 & $0.4(1.6)$ & 25.9 & $0.3(1.2)$ \\
\hline $\mathrm{C}$ & {$\left[45_{20} /-45_{20}\right]$} & 10 & 17.5 & 18.2 & $0.7(4)$ & 18.0 & $0.5(2.9)$ \\
\hline $\mathrm{D}$ & $\begin{array}{l}{\left[0_{5} / 45_{5} /-\right.} \\
\left.45_{5} / 90_{5}\right]\end{array}$ & 10 & 53.4 & 53.9 & $0.6(0.9)$ & 53.9 & $0.5(0.9)$ \\
\hline $\mathrm{E}$ & {$\left[0_{20} / 90 *_{1}\right]$} & 10 & 26.3 & 26.7 & $0.4(1.5)$ & 26.7 & $0.4(1.5)$ \\
\hline
\end{tabular}

*Note: All the heating elements are made only of CNT web except for sample E where $[90 *]_{1}$ represents 1 layer of $\mathrm{CF}$ thin ply, plus 2 layers of GFRP.

The use of cross-ply layers of CNT (or one CF thin ply) greatly improves the uniformity of heating (Fig. 4) in the CNT web element ${ }^{(18)}$. Moreover, it dramatically enhances heater resilience, to impact, with the point of impact showing up as a cold spot with only minor to minimal cooling in the zones to either side (Fig. 4) towards the distribution buses. The change in resistance following impact decreased from $10 \Omega$, or nearly $18 \%$ (Sample A) to less than 1 $\Omega$ or $4 \%$ when cross-ply layups were used (Table 1 ). After repair there is a small residual increase in resistance of up to $0.5 \Omega(2.9 \%)$ which possibly reflects the resistance of the CNT dispersion or incomplete reconnection of the broken CNT fringes. Optimisation of the CNT loading and dispersion, and application process are expected to further reduce this disparity. The linear unheated area seen in the unidirectional sample is almost eliminated by the use of a cross ply layup such as sample $\mathrm{D}$, which has a quasi-isotropic layup, being marginally more 
uniform than the other patterns. The actual damage locus is very evident in the cross-ply samples and readily repairable by the method described, with sample D again showing the best uniformity after repair.

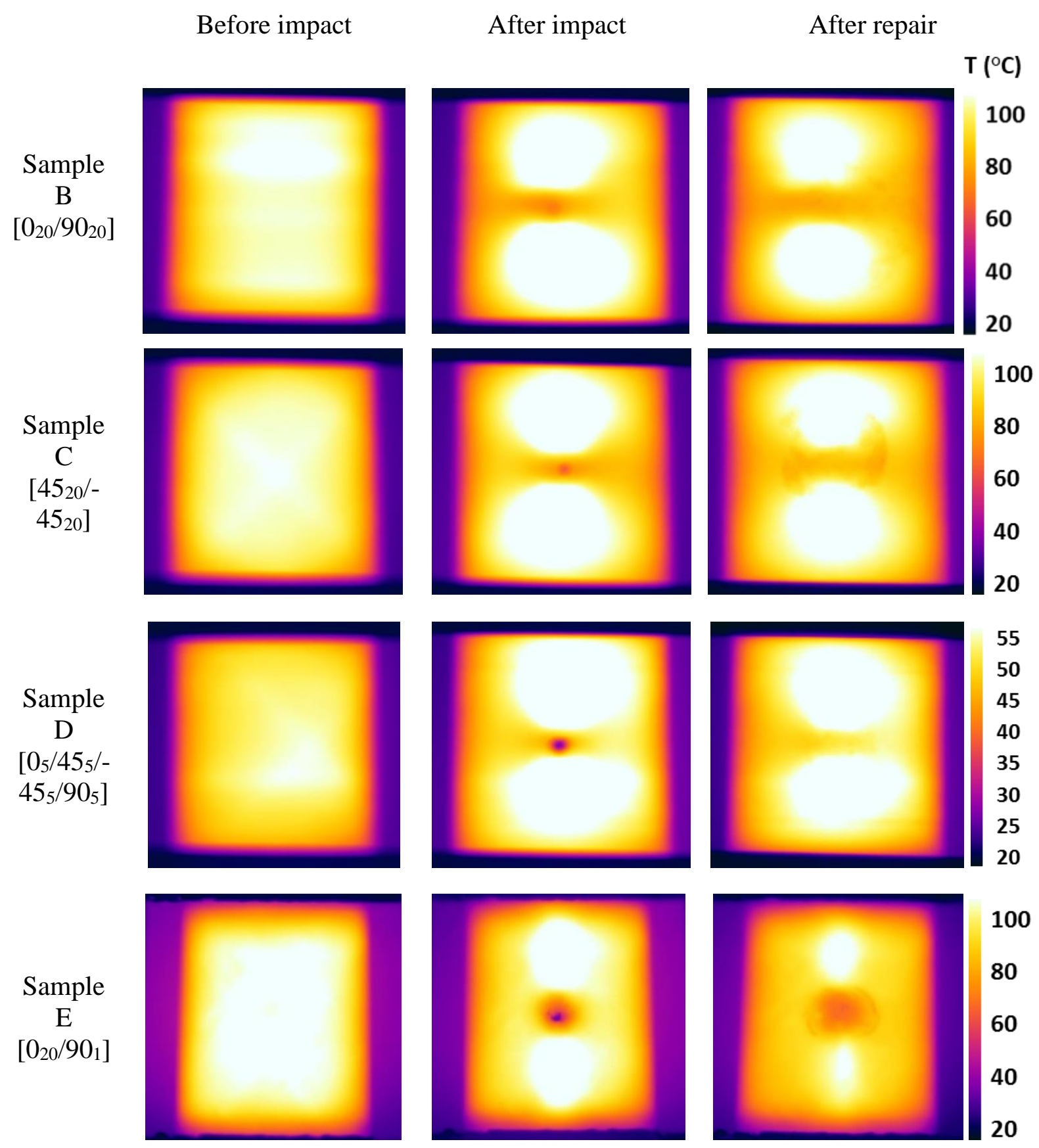

Figure 4. Heating performance of cross-ply samples with different layup before impact, after impact and after repair. 


\subsection{Flexibility of the CNT web based electro-thermal system}

In addition to its repairability and sensing function, the flexibility of the CNT web based electrothermal system was investigated with the CNT web layers $\left([0]_{15}\right)$ embedded between two layers of dry woven glass fabric (RE50P). The CNT/GFRP assembly was fabricated by vacuum assisted resin infusion using IN2 resin. After curing (Fig. 5a), the device was cut into the shape of a model wing leading edge section (Fig. 5b), and applied to its surface (Fig. 5c). The device was fabricated with unidirectional $\left(0^{\circ}\right) \mathrm{CNT}$ web, so the orthogonally oriented anisotropy of this structure results in the resistance increasing from $178 \Omega$ to $462 \Omega$ when cut from a rectangular (Fig 5a) to a chevron shape (Fig. 5b) to conform to the leading edge profile. At the maximum voltage (16 V) applied, the IR image (Fig. 5d) shows the highly conformal device as well as the effect of using the unidirectional CNT web, with the warmest zone corresponding to the most direct conduction path, as discussed in an earlier paper ${ }^{(13)}$.

(a)

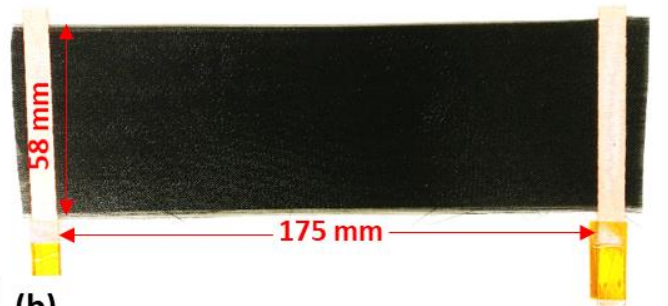

(b)

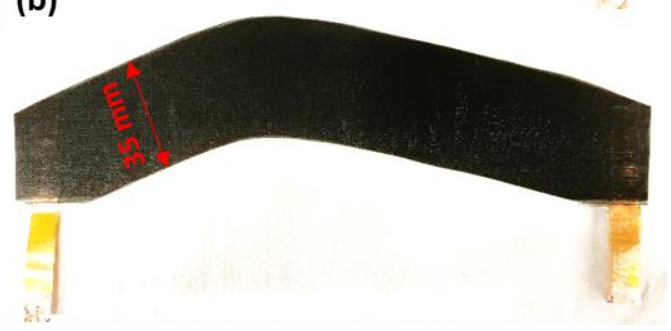

(c)

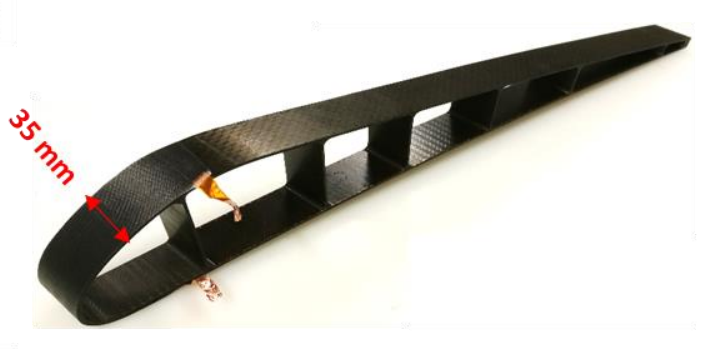

(d)

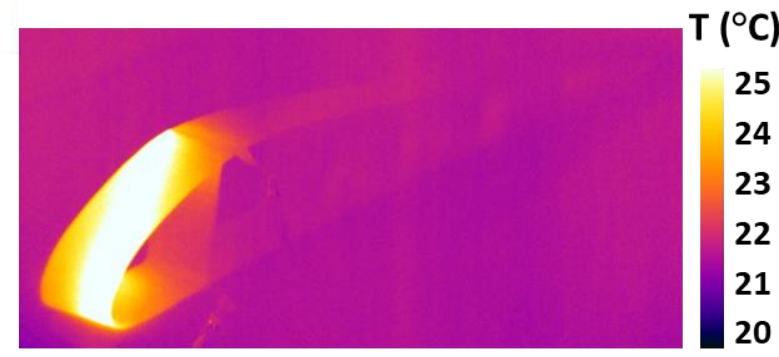

Figure 5. CNT web/glass fabric composite heater (a) original sample, (b) after being cut into a conformal shape, then (c) applied onto the aircraft wing section and (d) heating performance viewed by IR camera. 


\section{Conclusions}

Directly drawn CNT web has been demonstrated to produce a flexible, efficient, lightweight electro-thermal heating system. The CNT web is highly anisotropic with current flow primarily in the draw direction, so the layup pattern has a significant effect on the heating efficiency, thermal distribution and impact tolerance of the heater but also allowing for the design layup patterns to achieve a predictable heat distribution. The unidirectional layup, where there is very little transverse conductivity and hence pathway for current in the event of a breakage, after impact, exhibited near complete open circuit and heating failure in line with the damage. However, a method was developed so that this could be easily and quickly repaired with dispersed CNTs. Furthermore, through designing the layup, the heating element can be made much more resilient to damage with minimal change in resistance and performance as a result of impact damage whilst retaining the capacity to exhibit damage by IR photography. Repair is equally simple for such damage. In addition, the flexibility of the CNT-web based electrothermal system was demonstrated through fabricating a CNT/GF/epoxy composite and applying to the surface of the leading edge of a representative composite wing section.

\section{Acknowledgements}

The authors would like to acknowledge the financial support received from the European Union's 7th Framework Programme for Research under the Marie Curie Career Integration grant agreement No. 630756. We also acknowledge EP/N007190/1, the UK Engineering and Physical Sciences Research Council (EPRSC) grant.

\section{References}

1. MCCONNELL V.P. Past is prologue for composite repair. Reinf Plast. 2011, 55, (6), pp $17-21$. 
2. DIAMANTI K. and SOUTIS C. Structural health monitoring techniques for aircraft composite structures. Prog Aerosp Sci. 2010, 46, (8), pp 342-352.

3. GUEMES A., FERNANDEZ L.A., POZO A.R., SIERRA P.J. Structural health monitoring for advanced composite structures: a review. J Compos Sci. 2020, 4, (13), pp $1-15$.

4. KUMAR S., FALZON B.G., HAWKINS S.C. Ultrasensitive embedded sensor for composite joints based on a highly aligned carbon nanotube web. Carbon. 2019, 149, pp 380-389.

5. GAO L., CHOU T.W., ThOSTENSON E.T., ZHANG Z., COUlAUD M. In situ sensing of impact damage in epoxy/glass fiber composites using percolating carbon nanotube networks. Carbon. 2011, 49, (10), pp 3382-3385.

6. ZHANG B., SOLTANI S.A., LE L.N., ASMATULU R. Fabrication and assessment of a thin flexible surface coating made of pristine graphene for lightning strike protection. Mater Sci Eng B. 2017, 216, pp 31-40.

7. YAMASHITA S., HIRANO Y., SONEHARA T., TAKAHASHI J., KAWABE K., MURAKAMI T. Residual mechanical properties of carbon fibre reinforced thermoplastics with thin-ply prepreg after simulated lightning strike. Compos Part A. 2017, 101, pp185-194.

8. WANG B., DUAN Y., XIN Z., YAO X., ABLIZ D., ZIEGMANN G. Fabrication of an enriched graphene surface protection of carbon fiber/epoxy composites for lightning strike via a percolating-assisted resin film infusion method. Compos Sci Technol. 2018, 158, pp 51-60.

9. GUO Y., DONG Q., CHEN J., YAO X., YI X., JIA Y. Comparison between temperature and pyrolysis dependent models to evaluate the lightning strike damage of carbon fiber 
composite laminates. Compos Part A. 2017, 97, pp 10-18.

10. GUO Y., XU Y., WANG Q., DONG Q., YI X., JIA Y. Eliminating lightning strike damage to carbon fiber composite structures in Zone 2 of aircraft by Ni-coated carbon fiber nonwoven veils. Compos Sci Technol. 2019, 169, pp 95-102.

11. YAO X., FALZON B.G., HAWKINS S.C., TSANTZALIS S. Aligned carbon nanotube webs embedded in a composite laminate: A route towards a highly tunable electrothermal system. Carbon. 2018, 129, pp 486-494.

12. YAO X., HAWKINS S.C., FALZON B.G. An Advanced Anti-icing / De-icing system utilizing highly aligned carbon nanotube webs. Carbon. 2018, 136, pp130-138.

13. YAO X., FALZON B.G., HAWKINS S.C. Orthotropic electro-thermal behaviour of highly-aligned carbon nanotube web based composites. Compos Sci Technol. 2019, 170, pp 157-164.

14. TARFAOUI M., MOUMEN A.E., BOEHLE M., SHAH O., LAFDI K. Self-heating and deicing epoxy/glass fiber based carbon nanotubes buckypaper composite. J Mater Sci. 2019, 54, (2), pp 1351-1362.

15. IBRAHIM Y., KEMPERS R., AMIRFAZLI A. 3D printed electro-thermal anti- or deicing system for composite panels. Cold Reg Sci Technol. 2019, 166, pp 102844.

16. ZANGROSSI F., XU F., WARRIOR N., KARAPAPPAS P., HOU X. Electro-thermal and mechanical performance of multi-wall carbon nanotubes buckypapers embedded in fibre reinforced polymer composites for ice protection applications. J Compos Mater. 2020, 54, (23), pp 3457-3469.

17. REDONDO O., PROLONGO S.G., CAMPO M., SBARUfATTI C., GIGLIO M. Antiicing and de-icing coatings based Joule's heating of graphene nanoplatelets. Compos Sci Technol. 2018, 164, pp 65-73. 
18. ZHAO Z., CHEN H., LIU X., LIU H., ZHANG D. Development of high-efficient synthetic electric heating coating for anti-icing/de-icing. Surf Coatings Technol. 2018, 349, pp 340-346.

19. NISTAL A., FALZON B.G., HAWKINS S.C., CHITWAN R., GARCIA D.C., RUBIO F. Enhancing the fracture toughness of hierarchical composites through aminofunctionalised carbon nanotube webs. Compos Part B. 2019, 165, pp 537-544.

20. LEONARDO S.D., NiSTAL A., CATALANOTTI G., HAWKINS S.C., FALZON B.G. Mode I interlaminar fracture toughness of thin-ply laminates with CNT webs at the crack interface. Compos Struct. 2019, 225, pp 111178.

21. WICKS S.S., WANG W., WILLIAMS M.R., WARDLE B.L. Multi-scale interlaminar fracture mechanisms in woven composite laminates reinforced with aligned carbon nanotubes. Compos Sci Technol. 2014, 100, pp 128-135.

22. KALFON C.E., KOPP R., FURTADO C., Ni X., ARTEIRO A., BORSTNAR G., et al. Synergetic effects of thin plies and aligned carbon nanotube interlaminar reinforcement in composite laminates. Compos Sci Technol. 2018, 166, pp 160-168.

23. OU Y., GONZALEZ C., VILATELA J.J. Interlaminar toughening in structural carbon fiber/epoxy composites interleaved with carbon nanotube veils. Compos Part A. 2019, 124, pp 105477.

24. DONADON M.V., IANNUCCI L., FALZON B.G., HODGKINSON J.M., ALMEIDA S.F.M. A progressive failure model for composite laminates subjected to low velocity impact damage. Comput Struct. 2008, 86, pp 1232-1252.

25. FALZON B.G., ROBINSON P., FRENZ S., GILBERT B. Development and evaluation of a novel integrated anti-icing/de-icing technology for carbon fibre composite aerostructures using an electro-conductive textile. Compos Part A. 2015, 68, pp 323- 
335.

26. HEIMBS S., HELLER S., MIDDENDORF P., HAHNEL F., WEIBE J. Low velocity impact on CFRP plates with compressive preload: Test and modelling. Int J Impact Eng. 2009, 36, pp 1182-1193.

27. FAGGIANI A., FALZON B.G. Predicting low-velocity impact damage on a stiffened composite panel. Compos Part A. 2010, 41, (6), pp 737-749.

28. RUSSELlO M., DIAMANTI E.K., CATALANOTTI G., OHLSSON F., HAWKINS S.C., FALZON B.G. Enhancing the electrical conductivity of carbon fibre thin-ply laminates with directly grown aligned carbon nanotubes. Compos Struct. 2018, 206, pp 272-278.

29. ATKINSON K.R., HAWKINS S.C., HUYNH C., SKOURTIS C., DAI J., ZHANG M., et al. Multifunctional carbon nanotube yarns and transparent sheets: Fabrication, properties, and applications. Physica B. 2007, 394, pp 339-343.

30. HUYNH C.P., HAWKINS S.C. Understanding the synthesis of directly spinnable carbon nanotube forests. Carbon. 2010, 48, (4), pp 1105-1115.

31. YU M.F., LOURIE O., DYER M.J., MOLONI K., KELLY T.F., RUOFF R.S. Strength and breaking mechanism of multiwalled carbon nanotubes under tensile load. Science. 2000, 287, (5453), pp 637-640. 
(a)

(b)
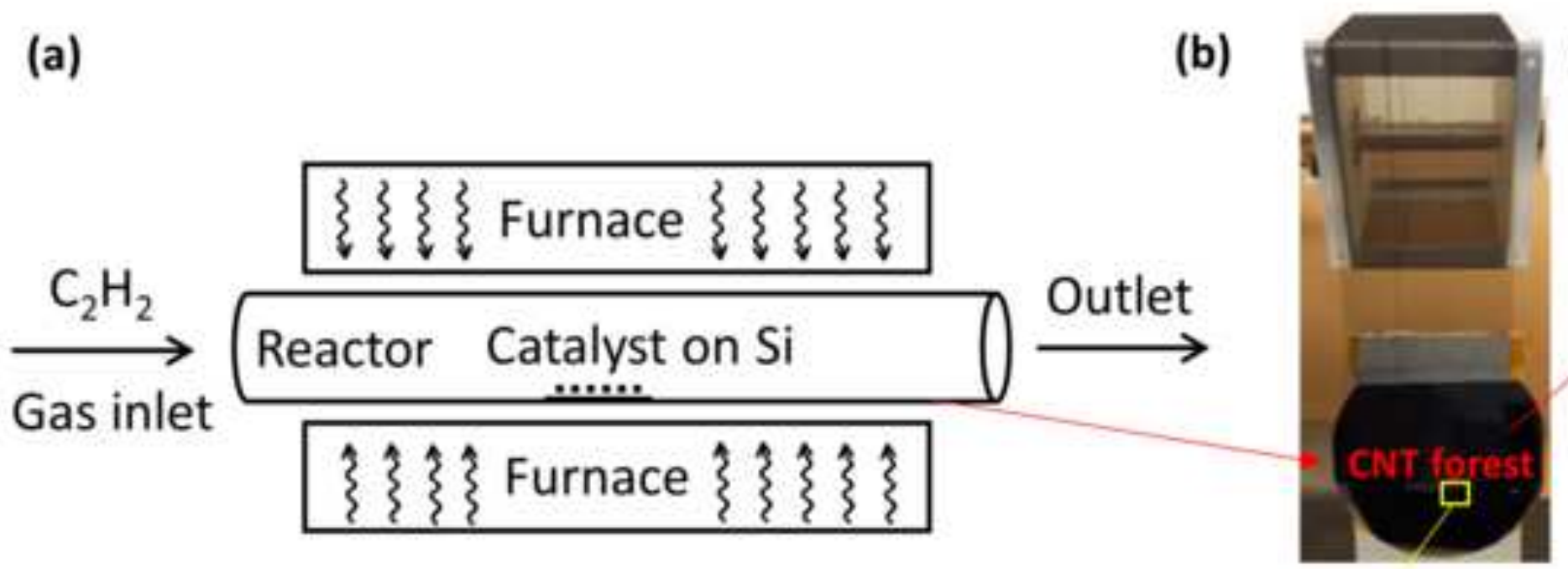

(c)
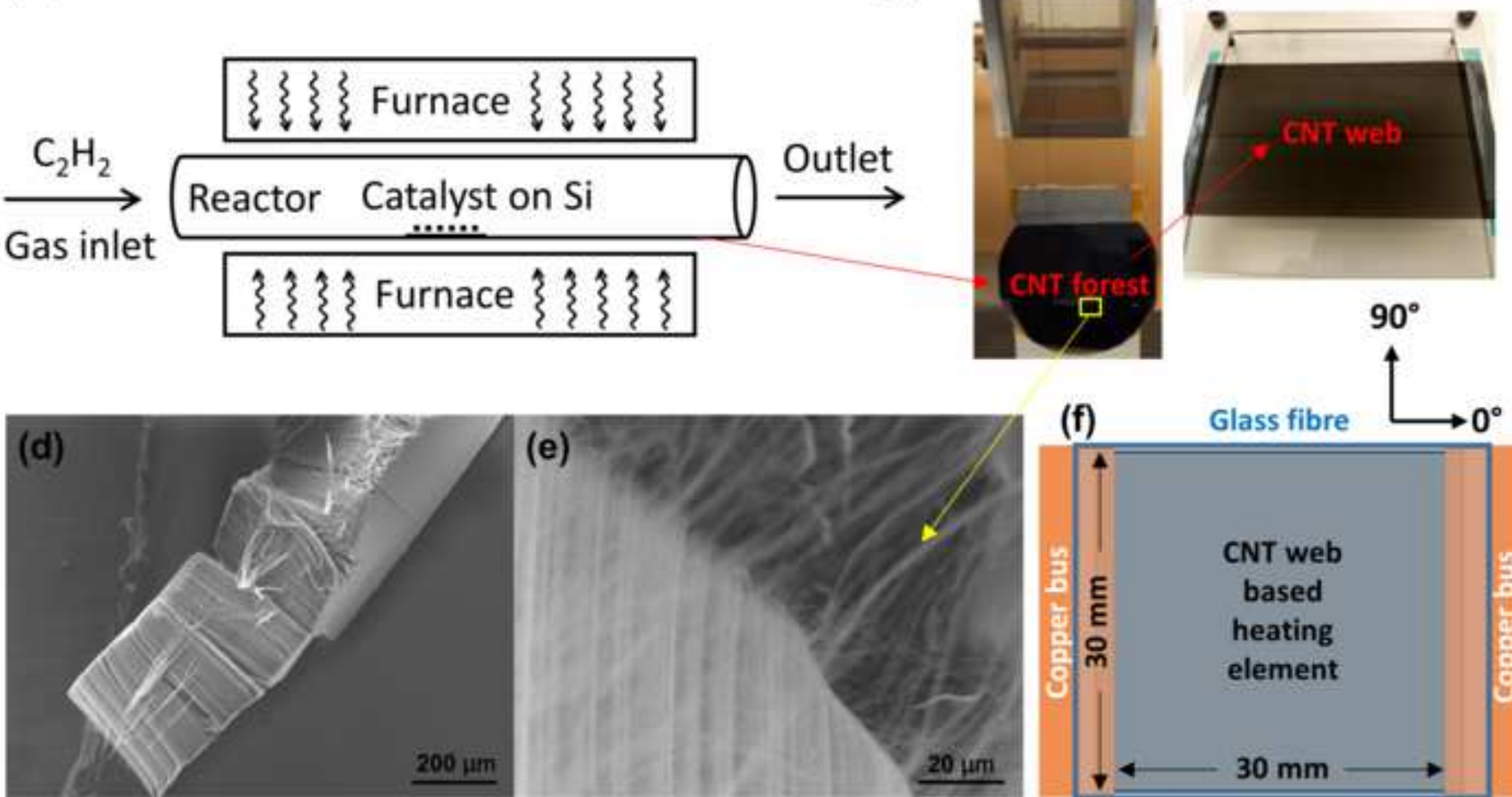

(f)
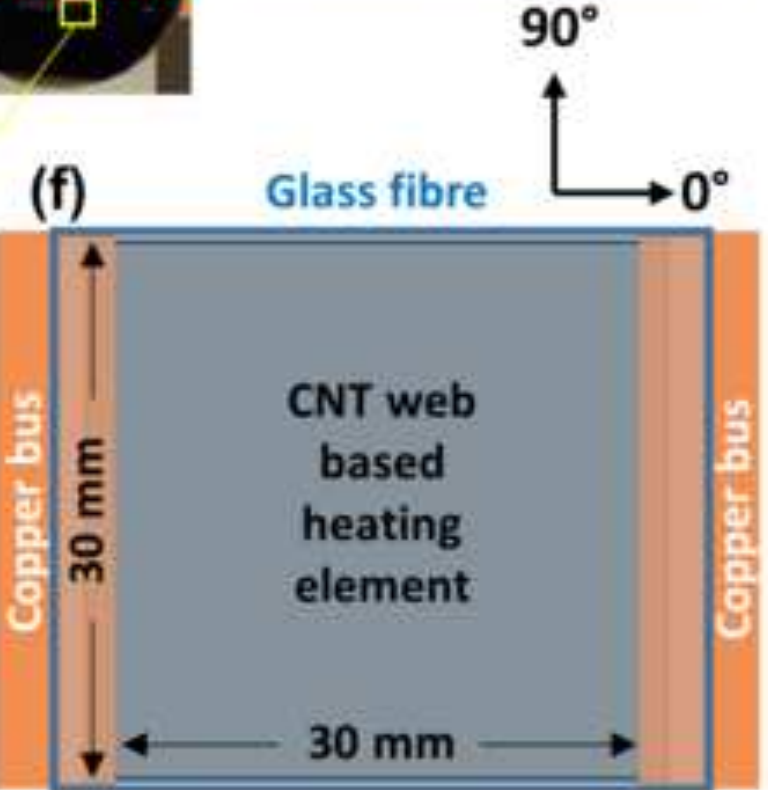

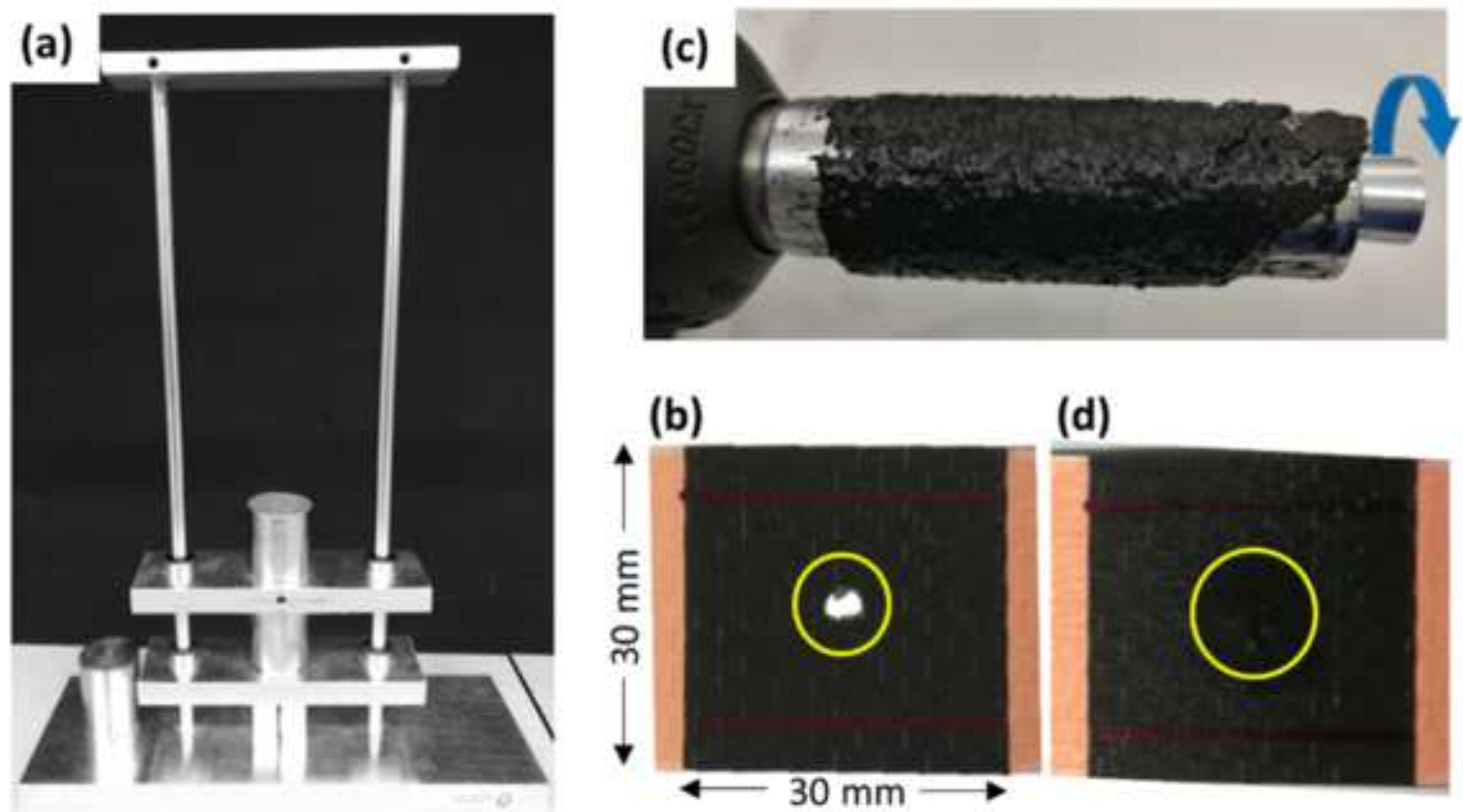

(b)

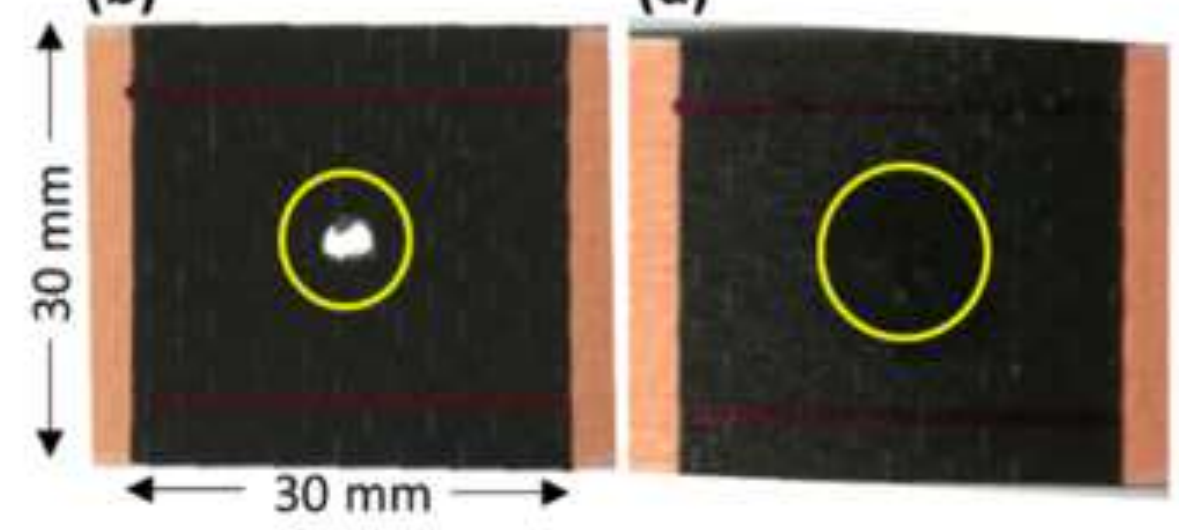

(e)

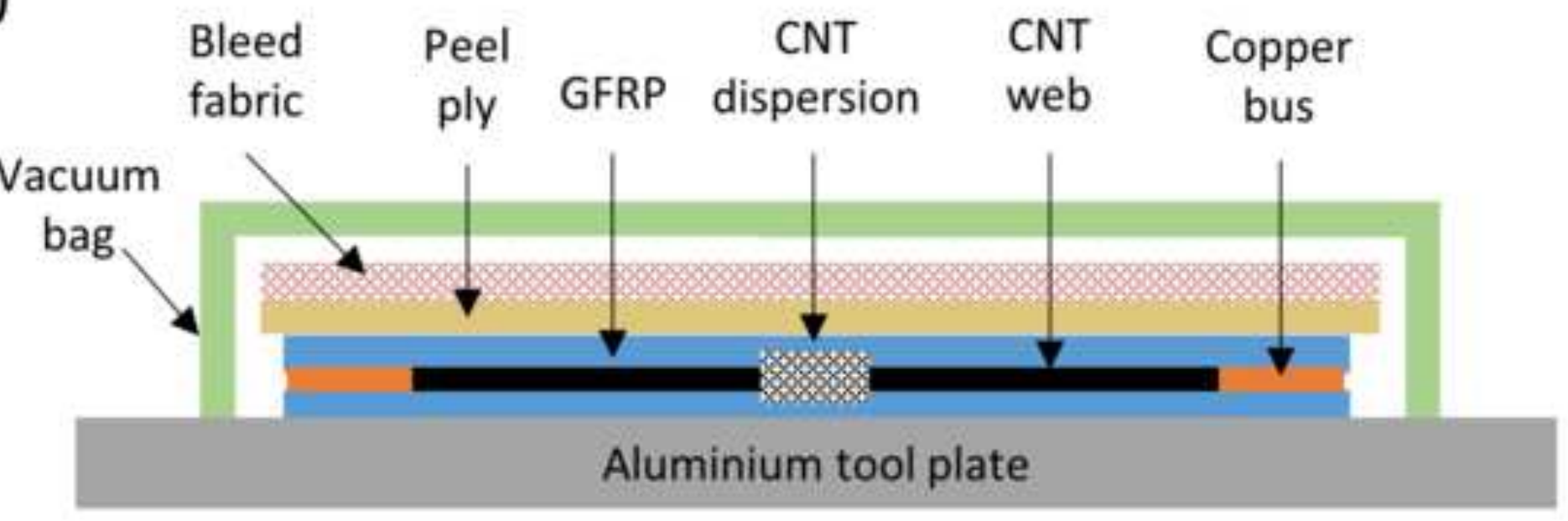




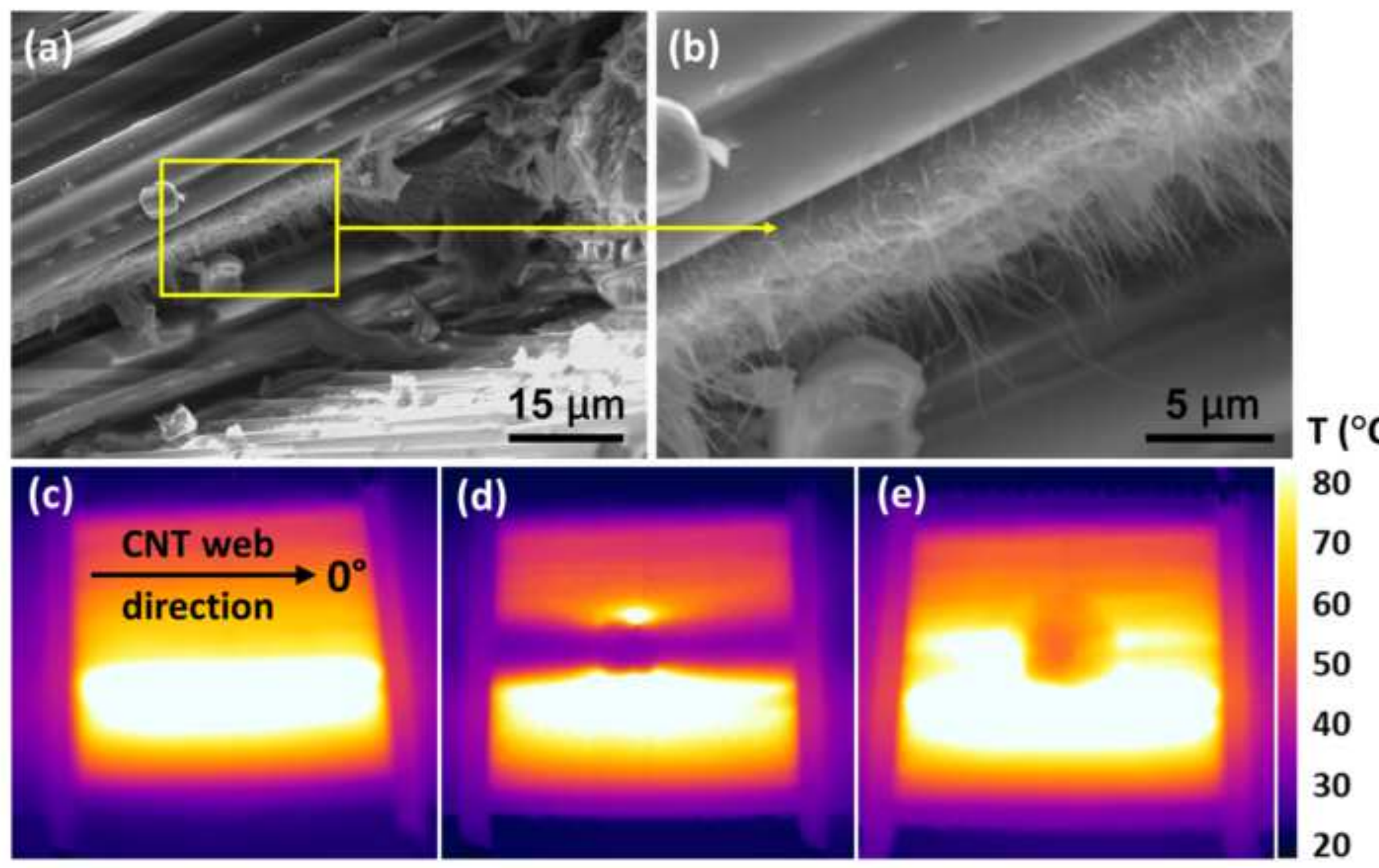




\section{Before impact}

\author{
Sample B \\ [0 $\mathrm{O}_{20} / 90_{20}$ ]
}

Sample C

$\left[45_{20} /-45_{20}\right.$ ]

Sample D

$\left[0_{5} / 45_{5}\right]$

$\left.-45_{5} / 90_{5}\right]$
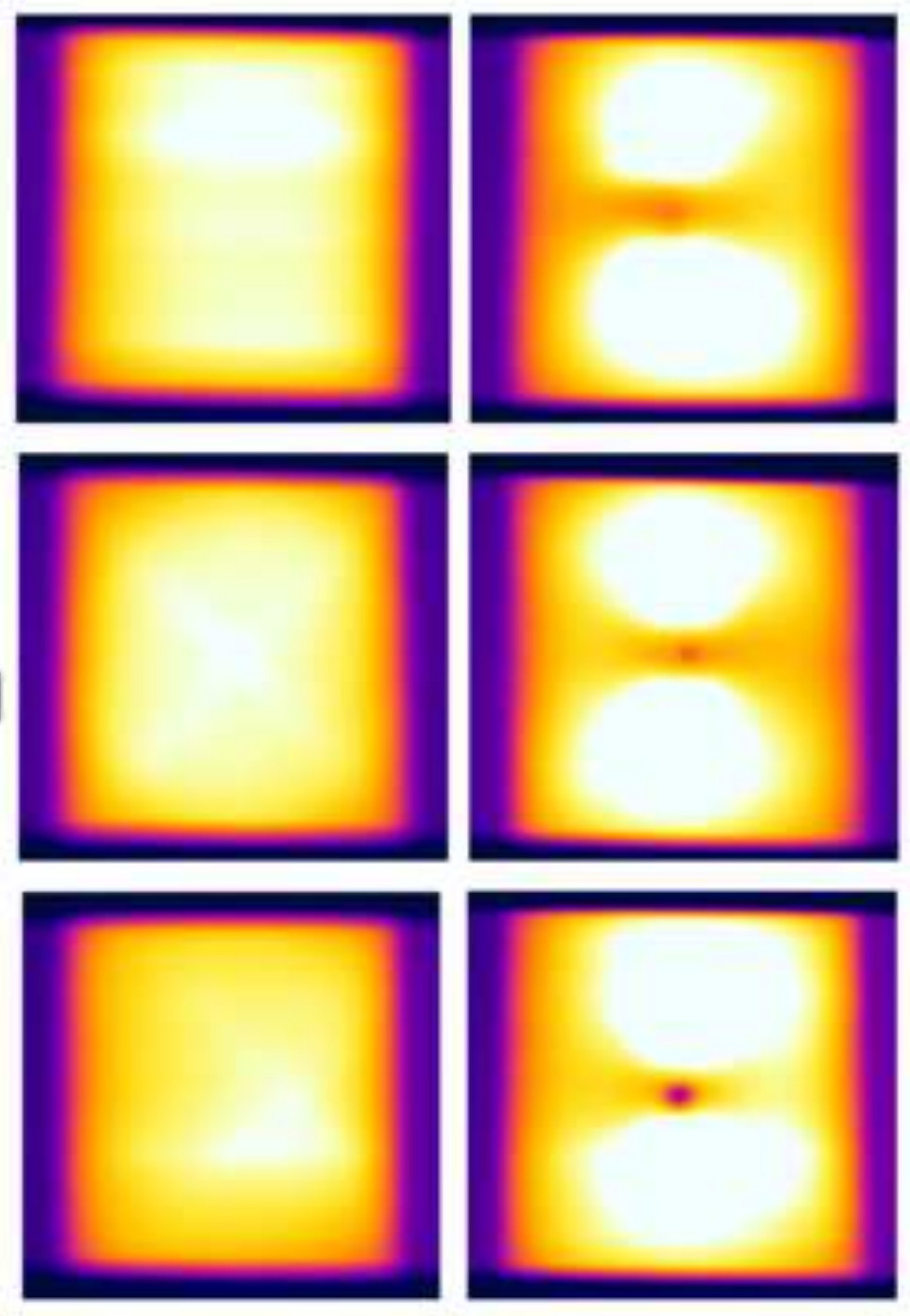

After impact

After repair
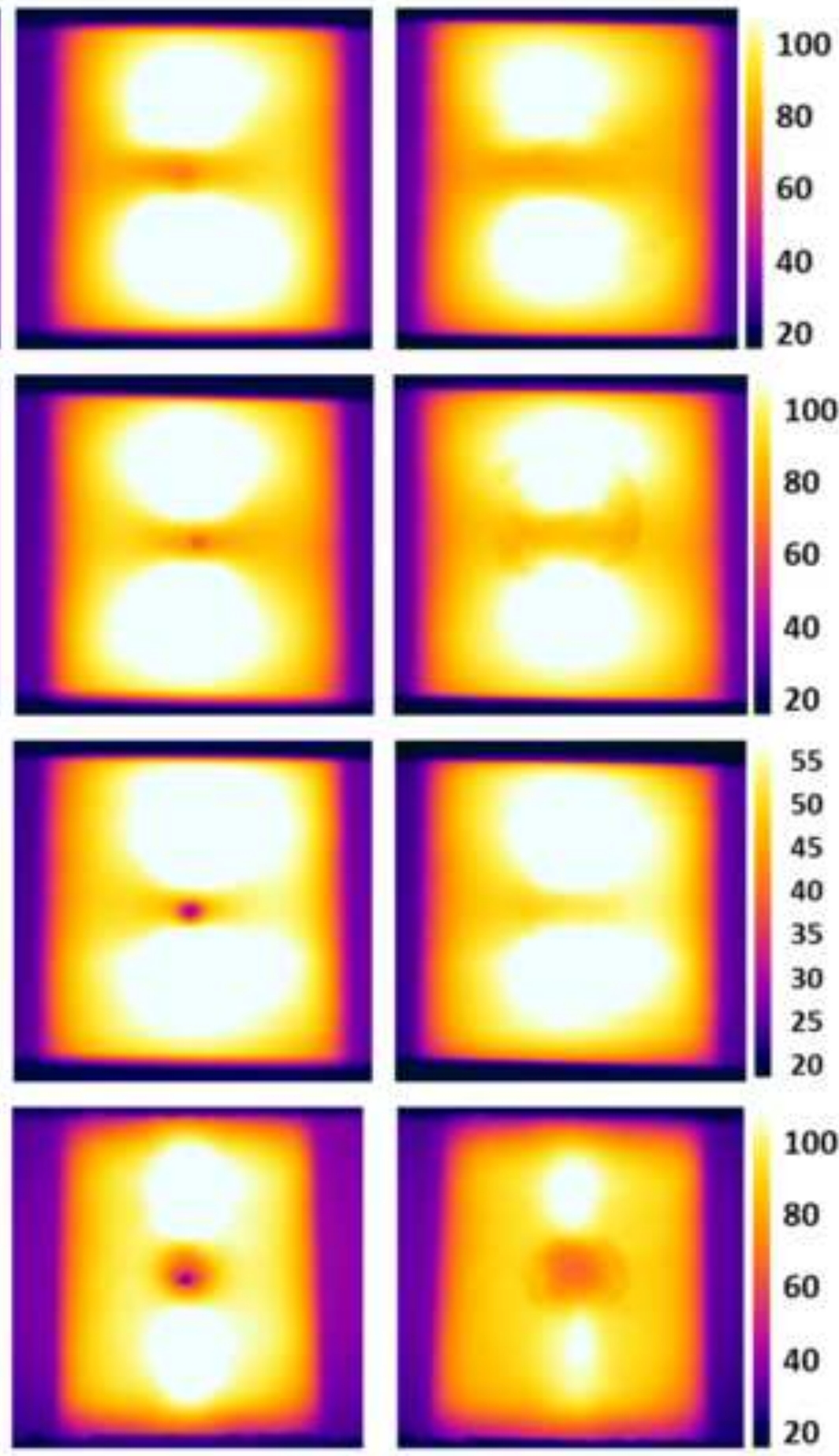

80

60

40

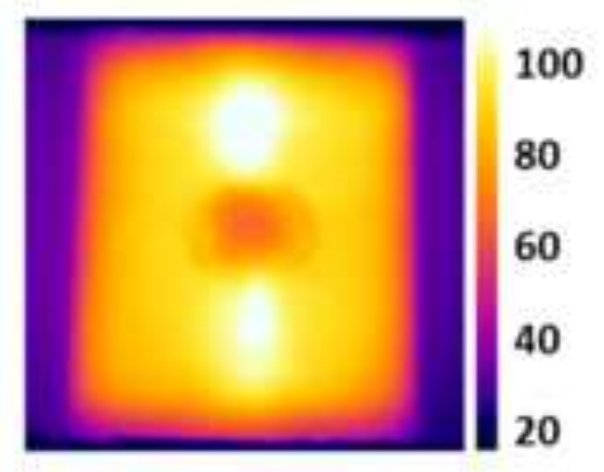

Sample E $\left[0_{20} / 90_{1}\right]$

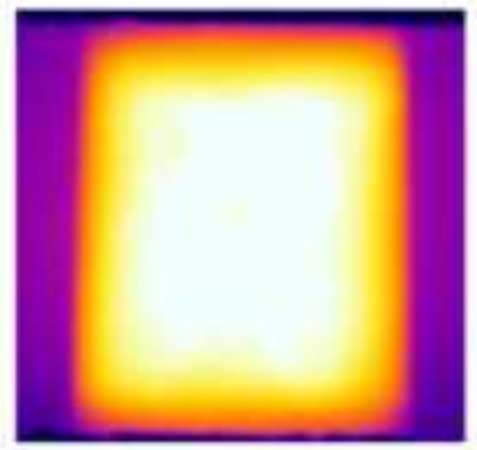


(a)

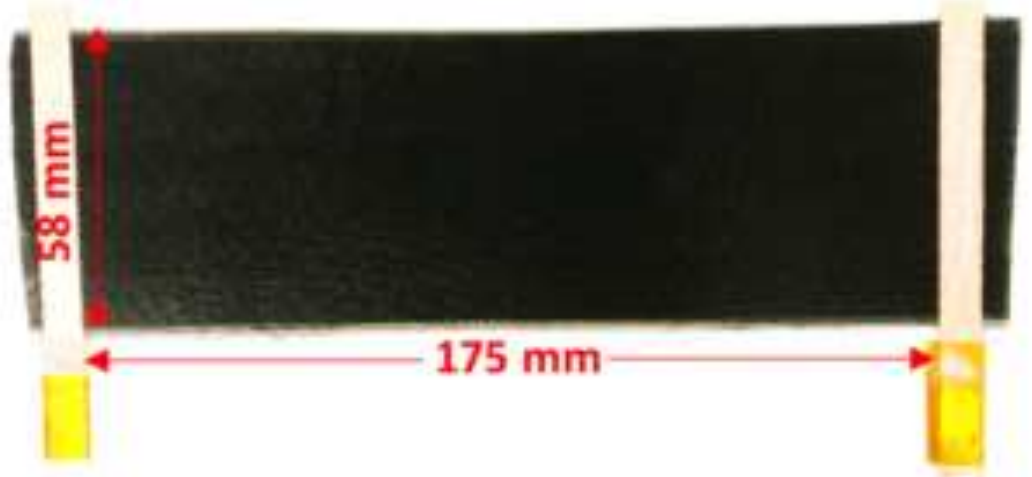

(b)

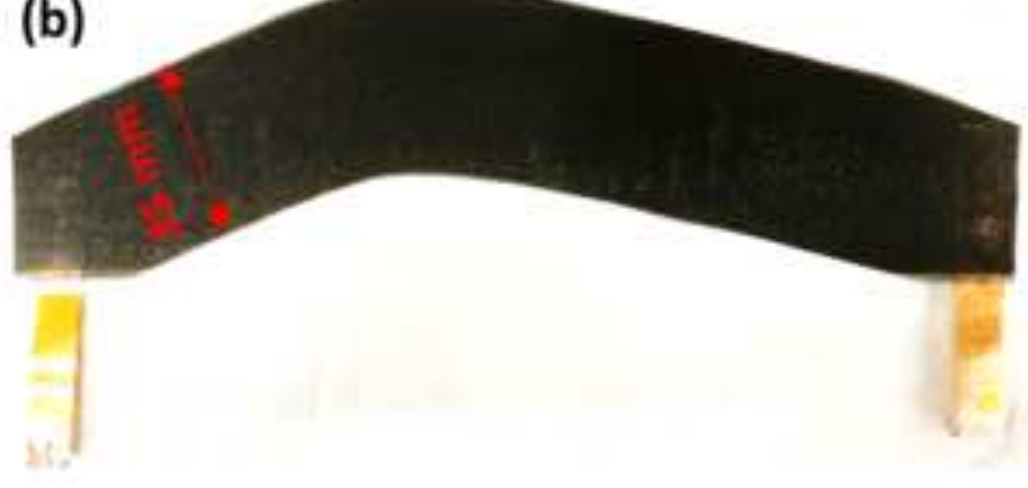

(c)

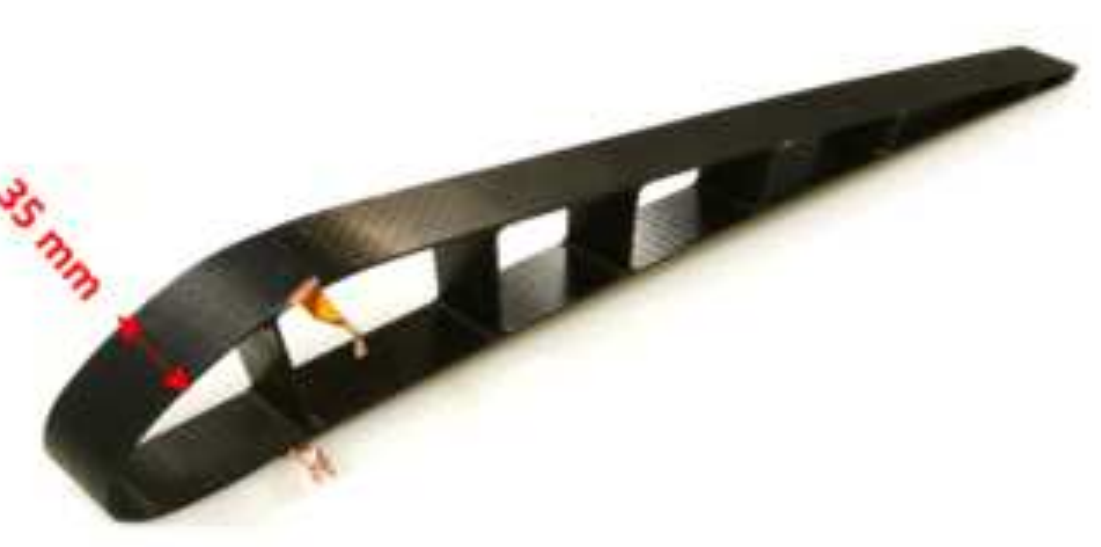

(d)

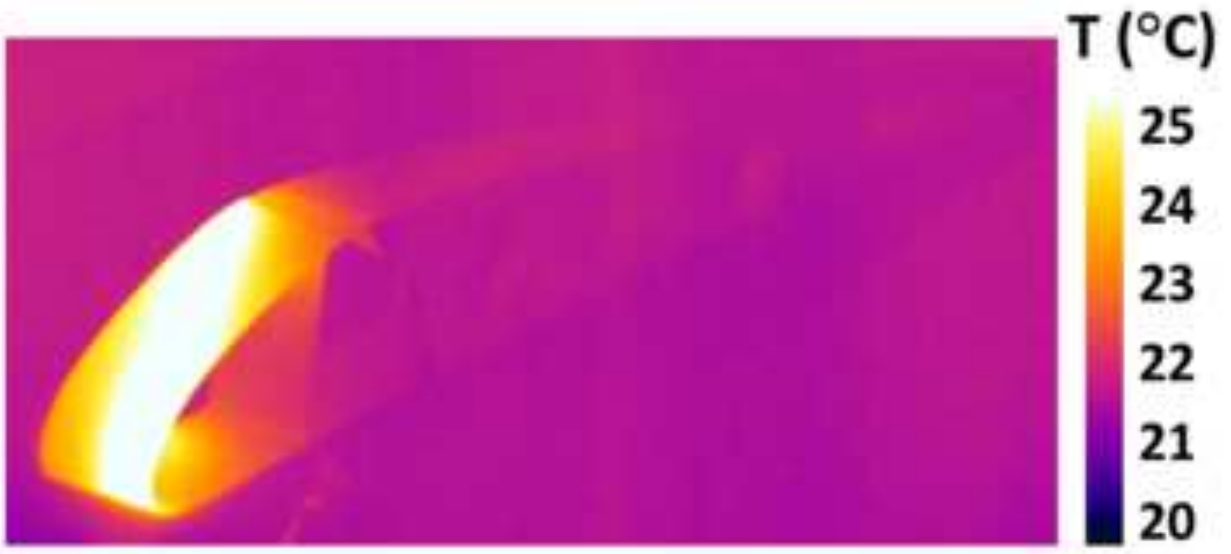

